\title{
Studies on Cure Behaviors, Dielectric Characteristics and Mechanical Properties of DGEBA/Poly(ethylene terephthalate) Blends
}

\author{
Soo-Jin Park* \\ Department of Chemistry, Inha University, Incheon 402-751, Korea \\ Received September 25, 2008; Revised January 11, 2009; Accepted January 12, 2009
}

\begin{abstract}
The cure behaviors, dielectric characteristics and fracture toughness of diglycidylether of bisphenol-A (DGEBA)/poly(ethylene terephthalate) (PET) blend system were investigated. The degree of conversion for the DGEBA/PET blend system was measured using Fourier transform infrared (FTIR) spectroscopy. The cure kinetics were investigated by measuring the cure activation energies $\left(E_{a}\right)$ with dynamic differential scanning calorimetry (DSC). The dielectric characteristic was examined by dielectric analysis (DEA). The mechanical properties were investigated by measuring the critical stress intensity factor $\left(K_{I C}\right)$, critical strain energy release rate $\left(G_{I C}\right)$, and impact strength test. As a result, DGEBA/PET was successfully blended. The $E_{a}$ of the blend system was increased with increasing PET content to a maximum at $10 \mathrm{phr}$ PET. The dielectric constant was decreased with increasing PET content. The mechanical properties of the blend system were also superior to those of the neat DGEBA. These results were attributed to the increased cross-linking density of the blend system, resulting from the interaction between the epoxy group of DGEBA and the carboxyl group of PET.
\end{abstract}

Keywords: DGEBA, PET, cure behaviors, dielectric characteristic, fracture toughness.

\section{Introduction}

Epoxy resins, with the properties of high adhesive strength, thermal resistance, electrical properties, chemical resistance and low shrinkage on cure, are extensively used in coating, electronic materials, adhesives and structural applications..$^{1-6}$ However, despite the advantages of the epoxy resins, they are commonly rigid and inherently brittle owing to the high cross-linking densities in curing, which is restricted to the last applications. ${ }^{7-9}$

In the past decades, many researchers have attempted to improve the toughness of highly cross-linked epoxy resins. Various of fillers have been used to bolster the toughness of epoxy resins. It is well known that the addition of rubber particles improves the toughness of epoxy resins. However, this method has a disadvantage in that in decreases the glass transition temperature $\left(T_{g}\right)$ of the cured resins. Therefore, many researchers have attempted to prepare composites from epoxy resins and other materials, such as modified composites including cross-linked structures, ${ }^{10,11}$ sequential interpenetrating polymer networks (IPNs), simultaneous IPNs, and semi-IPNs.

Recently, much research has been done into changing epoxy resins with high-performance engineering thermoplastics, such as poly(ether imide), polysulfone, ploly(ethylene tereph-

*Corresponding Author. E-mail: sjpark@inha.ac.kr thalate), and polyimide. ${ }^{12,13}$ Among these, poly(ethylene terephthalate) (PET) is one of most widely used thermoplastic polyesters; it has inherent advantages, such as good chemical resistance, modulus of elasticity, electrical insulating properties, and excellent mechanical properties. ${ }^{14-16}$

In this work, in order to improve the electrical insulating properties of epoxy resins, we perform DGEBA/PET blend system using PET as a high-performance engineering thermoplastic. This blend is expected to have better mechanical properties with epoxy resins because of the formation of hydrogen bonding between hydroxyl groups of DGEBA and carbonyl groups of PET. The characterization of the blend system is analyzed by Fourier-transform infrared (FTIR), differential scanning calorimeter (DSC), dielectric analysis (DEA), universal test machine (UTM), and scanning electron microscope (SEM) measurements.

\section{Experimental}

Materials. Aromatic epoxy resins, diglycidylether of bisphenol-A (DGEBA) in the form of YD-128 from Kukdo Chem. of Korea, were selected for blending. The epoxide equivalent weight (EEW) and density of DGEBA was 185-190 $\mathrm{g} / \mathrm{eq}$ and $1.16 \mathrm{~g} / \mathrm{cm}^{3}$ at $25^{\circ} \mathrm{C}$. 4,4'-Diaminodiphenyl methane (DDM, MO220) used as a curing agent was supplied from Tokyo Kasei Chem. Poly(ethylene terephthalate) (PET) (I.V, $0.65 \mathrm{Dl} / \mathrm{g}$ ) was purchased from Samyang Co., Ltd. Dichlo- 


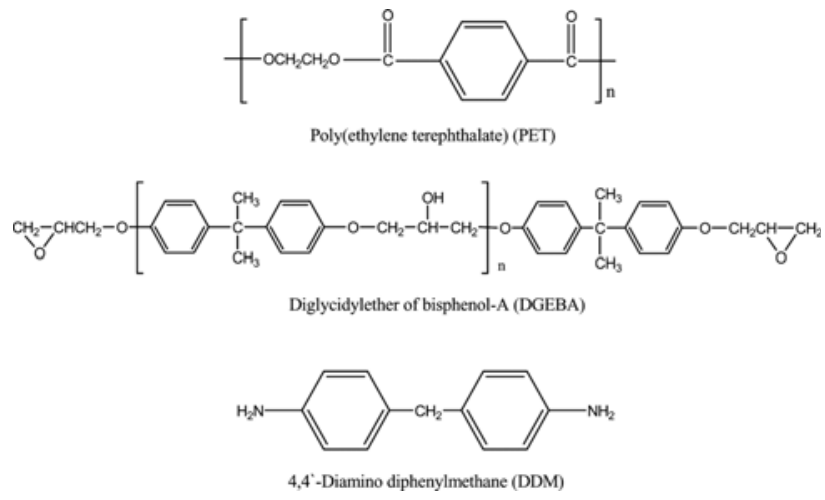

Figure 1. Chemical structures of PET, DGEBA, and DDM.

romethane (DCM); trichloroacetic acid (TCA) obtained from Duksan Pure Chemicals Co., Ltd. and Junsei Chemical Co., Ltd. was used without purification. The chemical structures of PET, DGEBA, and DDM are shown in Figure 1.

Sample Preparation. PET solution of $15 \mathrm{wt} \%$ was prepared by dissolution of PET in DCM (50 wt $\%$ ) and TCA (50 wt $\%$ ) solvent mixtures. The DGEBA was heated to melt at $70{ }^{\circ} \mathrm{C}$ for $15 \mathrm{~min}$ in the vial. After the DGEBA was melted, the DGEBA was blended with PET dissolved in acetone. The content of PET varied within 0, 5, 10, 15, $20 \mathrm{phr}$ to the DGEBA. After DDM (20 phr to the DGEBA) was added to the blends of DGEBA and PET, the samples were stirred at $80{ }^{\circ} \mathrm{C}$ for $<12 \mathrm{~h}$ to remove any residual solvent or to homogenize before pouring into the mold. Samples were degassed for $15 \mathrm{~min}$ in a vacuum oven at $70{ }^{\circ} \mathrm{C} .{ }^{17}$ The samples were then poured into a preheated glass mold, which was sprayed with a release agent (Release-All \#50, Aldrich) and put in a convection oven. The curing conditions of samples were as follows: $70{ }^{\circ} \mathrm{C}$ for $30 \mathrm{~min}, 110{ }^{\circ} \mathrm{C}$ for $2 \mathrm{~h}, 160{ }^{\circ} \mathrm{C}$ for $2 \mathrm{~h}$ and $200{ }^{\circ} \mathrm{C}$ for $1 \mathrm{~h}$.

Measurements. Fourier-transform infrared (FTIR) was used to verify the degree of conversion of the blend system. FTIR spectroscopy was performed with a Jasco Co. FT/IR4200 spectrometer.

The cure behaviors of the blend system were measured using a differential scanning calorimeter (Perkin-Elmer Co., DSC-6) between 30 and $300{ }^{\circ} \mathrm{C}$ under a nitrogen flow of $30 \mathrm{~mL} / \mathrm{min}$. The cure kinetics were investigated by measurement of the cure activation energies $\left(E_{a}\right)$ with the dynamic DSC method. Temperature scans were performed at different heating rates $\left(5,10,15\right.$, and $\left.20{ }^{\circ} \mathrm{C} / \mathrm{min}\right)$.

The frequency-dependent dielectric measurement was investigated using a dielectric spectrometer (Novocontrol $\mathrm{GmbH}$, CONCEPT 40). The diameter of the electrode and the blend system was $30 \mathrm{~mm}$. To promote good electrical contact between the electrode and the blend system, before measurement the blend system was coated on both sides with a silver layer. The frequency used for the measurement was $10^{0}-10^{7} \mathrm{~Hz}$ at room temperature and the dielectric con- stant was monitored.

The mechanical interfacial properties of the blend system were measured using a fracture toughness and impact strength. The fracture toughness, as quantified by the critical stress intensity factor $\left(K_{I C}\right)$, was determined using a single-edge notched (SEN) test in a three-point bending test, which was performed on a universal test machine (UTM, LR5K Plus, Lloyd). The specimen geometry satisfies the requirements for condition as indicated in ASTM E 399. Span-to-depth ratios of $4 / 1$ and crosshead speeds of $1 \mathrm{~mm} / \mathrm{min}$ were used. Impact strength test was performed using an Izod impact tester (Toyoseki Co.) according to ASTM D 256.

In order to investigate the phase morphologies of the blend system, the fractured surface of the specimens after the SEN fracture toughness test was examined by using a scanning electron microscope (SEM, HITACHI S-4200).

\section{Results and Discussion}

Cure Behaviors. FTIR can be used to investigate the structural differences between DGEBA and DGEBA/PET blend systems. Figure 2 shows the FTIR spectra of DGEBA/ PET blend system. The spectrum of PET, a characteristic absorption peak of carbonyl group $(\mathrm{C}=\mathrm{O})$ can be observed at $1715 \mathrm{~cm}^{-1}$. The characteristic absorption peak of the DGEBA appear near $1300-1000 \mathrm{~cm}^{-1}$ (C-O in ester), $1465 \mathrm{~cm}^{-1}$ (- $\mathrm{CH}_{2}$ - in alkanes), $1000-650 \mathrm{~cm}^{-1}$ (C-H in alkenes) and $3500-3100 \mathrm{~cm}^{-1}$ (N-H in amide). After PET blending, the characteristic absorption peak of the blend system appear near $3400-3200 \mathrm{~cm}^{-1}$ (O-H in carboxylic). It can be estimated that blending of DGEBA/PET progressed successfully.

Figure 3 shows the DSC thermograms of the blend system. Kinetic analysis of the DSC data for the blend system is performed using two kinetic models: Kissinger and Freeman-Carroll methods. The DSC scans at different heating rates allowed us to determine the cure activation energy $\left(E_{a}\right)$ of the blend system by the Kissinger method; ${ }^{18}$

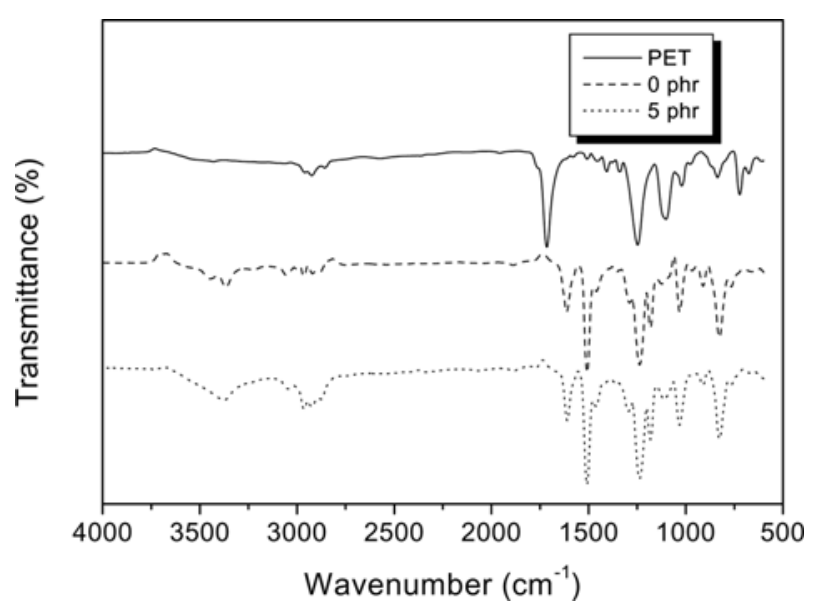

Figure 2. FTIR spectra of DGEBA/PET blend system. 


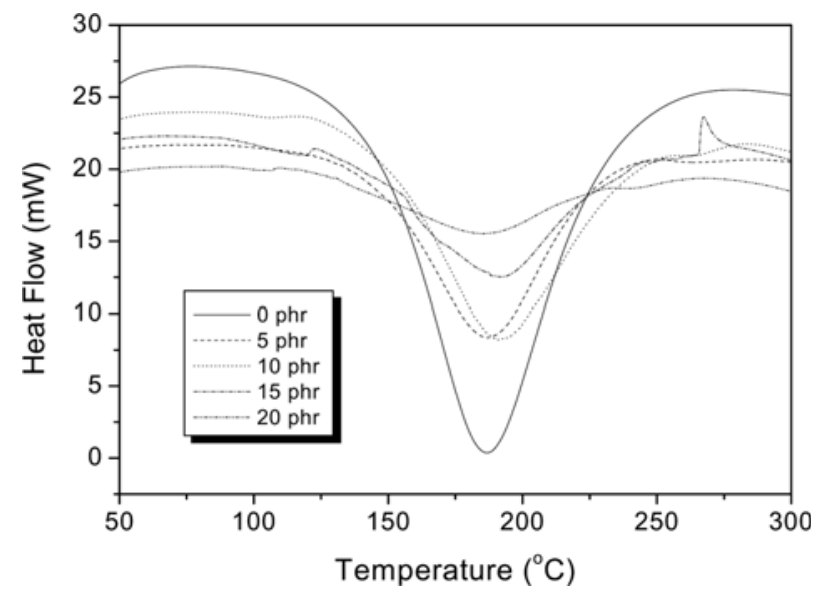

Figure 3. DSC thermograms of DGEBA/PET blend system (heating rate: $20^{\circ} \mathrm{C} / \mathrm{min}$ ).

$$
\frac{\phi}{T_{m}^{2}}=\frac{R A}{E_{a}} e^{\frac{E_{a}}{R T_{m}}}
$$

where, $\phi$ is the heating rate; $T_{m}$ is the temperature of the maximum exothermic peak; $A$ is the pre-exponential factor; and $R$ is the gas constant.

$E_{a}$ can be calculated using the slope of the graph $\ln \left(\phi / T_{m}{ }^{2}\right)$ versus $\left(1 / T_{m}\right)$ on the basis of eq. (1). In Figure 4 , the experimental values of $\ln \left(\phi / T_{m}{ }^{2}\right)$ are plotted as a function of the reciprocal cure temperature $\left(1 / T_{m}\right)$. The values of $E_{a}$ are listed in Table I.

The Freeman-Carroll method is applicable to cure behaviors and offers a rapid and simple technique. The cure activation energy and reaction order can be calculated using the following relationship: ${ }^{19}$

$$
-\frac{\Delta \ln d H / d t}{\Delta \ln (\Delta H-H)}=n-\frac{E_{a} / R \times \Delta 1 / T}{\Delta \ln (\Delta H-H)}
$$

where, $d H / d t$ is the heat flow, generated in the curing reac-

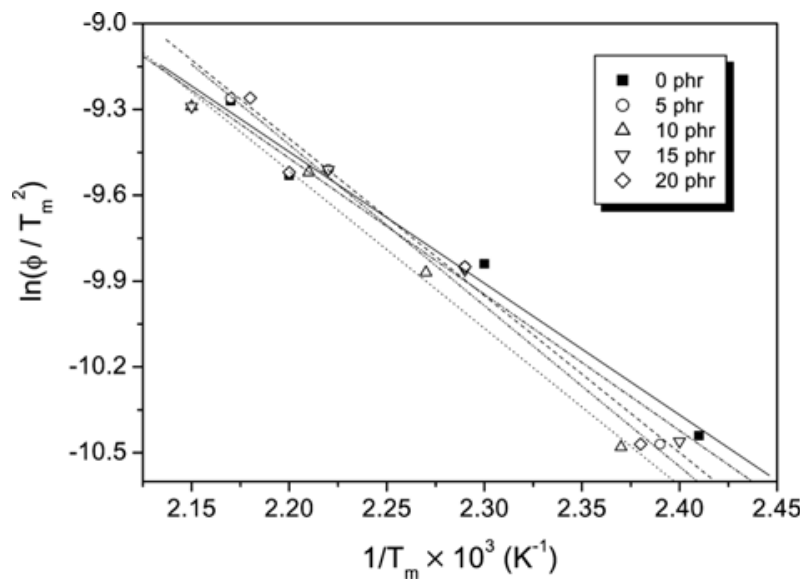

Figure 4. $\ln \left(\phi / T_{m}{ }^{2}\right) v s\left(1 / T_{m}\right)$ plot for determining the cure activation energy.

tion $(\mathrm{W} / \mathrm{g}) ; \Delta H$ is the total heat of curing $(\mathrm{kJ} / \mathrm{mol}) ; n$ is the reaction order; $E_{a}$ is the cure activation energy; $R$ is the gas constant; and $T$ is the absolute temperature $(K)$.

The relationship (2) may be represented by a straight line described by the equation:

$$
y=m x-c
$$

where, $m=E_{a} / R$ and $c=n$. The cure activation energies and reaction order are listed in Table II.

Kinetic analysis results of the DSC data for the blend system show that the cure activation energies $\left(E_{a}\right)$ are increased in 10 phr of PET with neat DGEBA, due to the increasing intermolecular interaction between DGEBA and PET. When the PET content increased above $10 \mathrm{phr}$, the cure activation energies decreased, due to the increasing incomplete crosslink of the DGEBA network.

Dielectric Characteristics. The dielectric constant of the blend system was measured by dielectric spectrometer in a

\begin{tabular}{|c|c|c|c|c|c|c|}
\hline \multirow{2}{*}{ DGEBA/PET } & \multirow{2}{*}{ Kinetic Factor } & \multicolumn{4}{|c|}{ Heating Rate $\left({ }^{\circ} \mathrm{C} / \mathrm{min}\right)$} & \multirow{2}{*}{$E_{a}(\mathrm{~kJ} / \mathrm{mol})$} \\
\hline & & 5 & 10 & 15 & 20 & \\
\hline \multirow{2}{*}{$0 \mathrm{phr}$} & $\left(1 / T_{m}\right) \times 10^{-3}$ & 2.41 & 2.3 & 2.2 & 2.17 & \multirow{2}{*}{38} \\
\hline & $\ln \left(\phi / T_{m}^{2}\right)$ & -10.44 & -9.84 & -9.53 & -9.27 & \\
\hline \multirow{2}{*}{$5 \mathrm{phr}$} & $\left(1 / T_{m}\right) \times 10^{-3}$ & 2.39 & 2.29 & 2.22 & 2.17 & \multirow{2}{*}{46} \\
\hline & $\ln \left(\phi / T_{m}^{2}\right)$ & -10.47 & -9.85 & -9.51 & -9.26 & \\
\hline \multirow{2}{*}{$10 \mathrm{phr}$} & $\left(1 / T_{m}\right) \times 10^{-3}$ & 2.37 & 2.27 & 2.21 & 2.15 & \multirow{2}{*}{46} \\
\hline & $\ln \left(\phi / T_{m}^{2}\right)$ & -10.48 & -9.87 & -9.52 & -9.29 & \\
\hline \multirow{2}{*}{$15 \mathrm{phr}$} & $\left(1 / T_{m}\right) \times 10^{-3}$ & 2.4 & 2.29 & 2.22 & 2.15 & \multirow{2}{*}{40} \\
\hline & $\ln \left(\phi / T_{m}^{2}\right)$ & -10.46 & -9.86 & -9.51 & -9.29 & \\
\hline \multirow{2}{*}{$20 \mathrm{phr}$} & $\left(1 / T_{m}\right) \times 10^{-3}$ & 2.38 & 2.29 & 2.2 & 2.18 & \multirow{2}{*}{36} \\
\hline & $\ln \left(\phi / T_{m}^{2}\right)$ & -10.47 & -9.92 & -9.72 & -9.54 & \\
\hline
\end{tabular}
wide frequency. The dielectric constant was calculated by

Table I. Cure Activation Energy $\left(E_{a}\right)$ Obtained by the Kissinger Equation 
Table II. Cure Activation Energy $\left(E_{a}\right)$ and Reaction Order (n) Obtained by the Freeman-Carroll Equation

\begin{tabular}{cccc}
\hline DGEBA/PET & Heating Rate $\left({ }^{\circ} \mathrm{C} / \mathrm{min}\right)$ & $n$ & $E_{a}(\mathrm{~kJ} / \mathrm{mol})$ \\
\hline \multirow{3}{*}{$0 \mathrm{phr}$} & 5 & 0.16 & 12.0 \\
& 10 & 0.25 & 14.5 \\
& 15 & 0.22 & 14.3 \\
& 20 & 0.19 & 14.0 \\
\hline \multirow{3}{*}{$5 \mathrm{phr}$} & 5 & 0.35 & 15.2 \\
& 10 & 0.41 & 18.1 \\
& 15 & 0.13 & 13.0 \\
$10 \mathrm{phr}$ & 20 & 0.50 & 22.0 \\
& 5 & 0.33 & 15.0 \\
& 10 & 0.31 & 15.9 \\
& 15 & 0.41 & 19.0 \\
& 20 & 0.49 & 22.2 \\
\hline \multirow{3}{*}{$15 \mathrm{phr}$} & 5 & 0.30 & 14.8 \\
& 10 & 0.47 & 19.0 \\
& 15 & 0.24 & 15.6 \\
& 20 & 0.25 & 15.6 \\
\hline \multirow{3}{*}{0} & 10 & 0.22 & 13.2 \\
& 5 & 0.36 & 16.2 \\
& 15 & 0.32 & 16.7 \\
& 20 & 0.17 & 13.9 \\
\hline
\end{tabular}

using the equation: $:^{20}$

$$
\varepsilon_{r}=\frac{C \times D}{\varepsilon_{0} \times A}
$$

where, $\varepsilon_{0}$ is the permittivity of free space $\left(8.85 \times 10^{-14} \mathrm{~F} / \mathrm{cm}\right)$; $\varepsilon_{r}$ is the permittivity of the blend system; $C$ is the capacitance; $D$ is the blend system thickness; and $A$ is the electrode area.

Figure 5 shows the variety of dielectric constants of neat DGEBA and the blend system measured at frequencies of $10^{0}-10^{7} \mathrm{~Hz}$. The dielectric constant of the blend system is decreased with increasing the frequency and PET content. It can be seen that the dielectric constant of the blend system shows a lower value than that of neat DGEBA. These results can be attributed to addition of PET into the DGEBA and thus causing the charge migration, resulting in decreasing the dielectric constant in the blend system. $^{21}$

Mechanical Properties. The critical stress intensity factor $\left(K_{I C}\right)$, critical strain energy release rate $\left(G_{I C}\right)$, and impactstrength are used to evaluate the fracture properties of the blend system. The $K_{I C}$ values were calculated using the following relationship: ${ }^{22}$

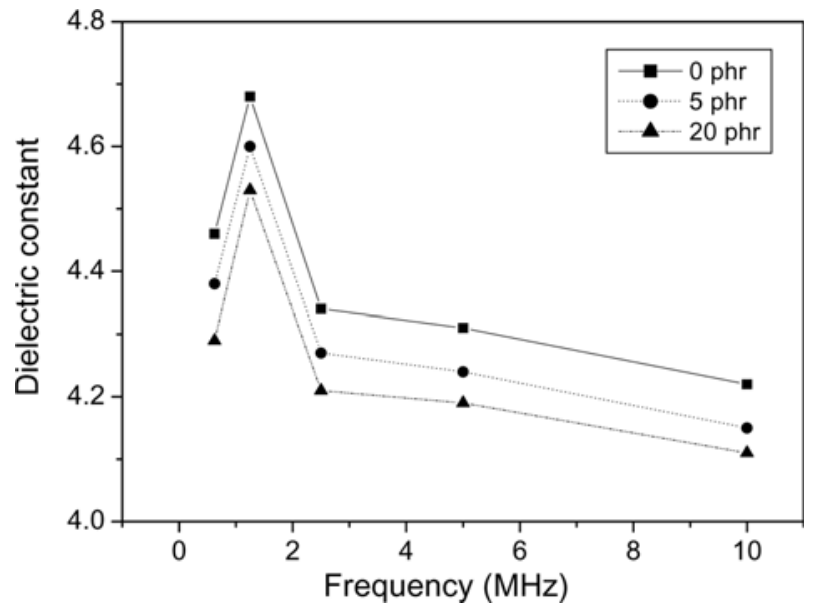

Figure 5. Dielectric constants of DGEBA/PET blend system.

$$
K_{I C}=\frac{P L}{b d^{3 / 2}} Y
$$

where $P$ is the rupture force, $L$ the span between the supports, and $Y$ the geometrical factor; $b$ and $d$ are the specimen width and thickness, respectively.

The $G_{I C}$ values were calculated using the $K_{I C}$ and following relationship: $:^{23}$

$$
G_{I C}=\frac{\left(1-v^{2}\right) K_{I C}^{2}}{E}
$$

where $v$ is Poisson's ratio ( $v=0.3$ is calculated in this work) and $E$ is the tensile modulus obtained from fracture testing.

Figures 6 and 7 show the $K_{I C}$ and $G_{I C}$ values of the blend system prepared with different contents of PET. With increase of PET content to $10 \mathrm{phr}$ PET, the $K_{I C}$ values of the blend system increase gradually from 3.37 to $4.09 \mathrm{MPa} \cdot \mathrm{m}^{1 / 2}$. When the PET content increased above $10 \mathrm{phr}$, however, the $K_{I C}$ values of the blend system decreased. The $K_{I C}$ and $G_{I C}$ values

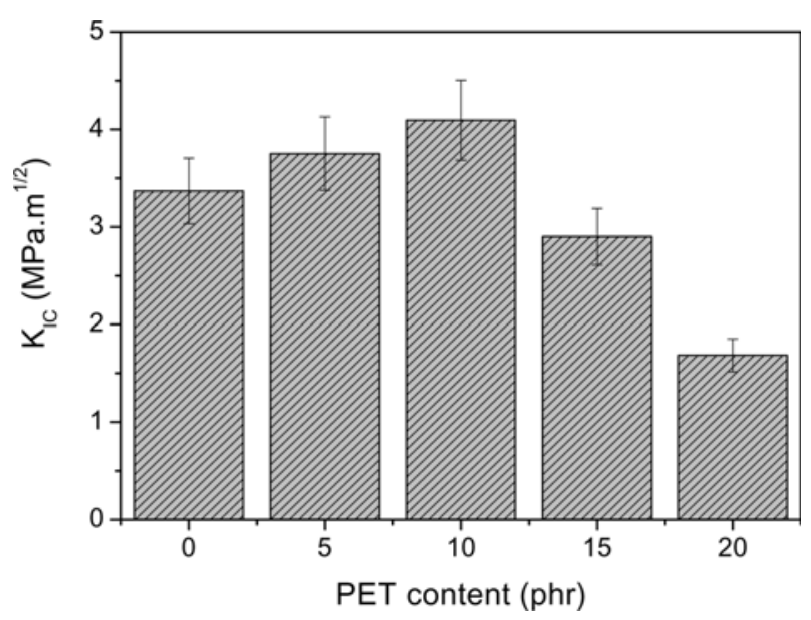

Figure 6. $K_{I C}$ values of DGEBA/PET blend system as a function of PET content. 


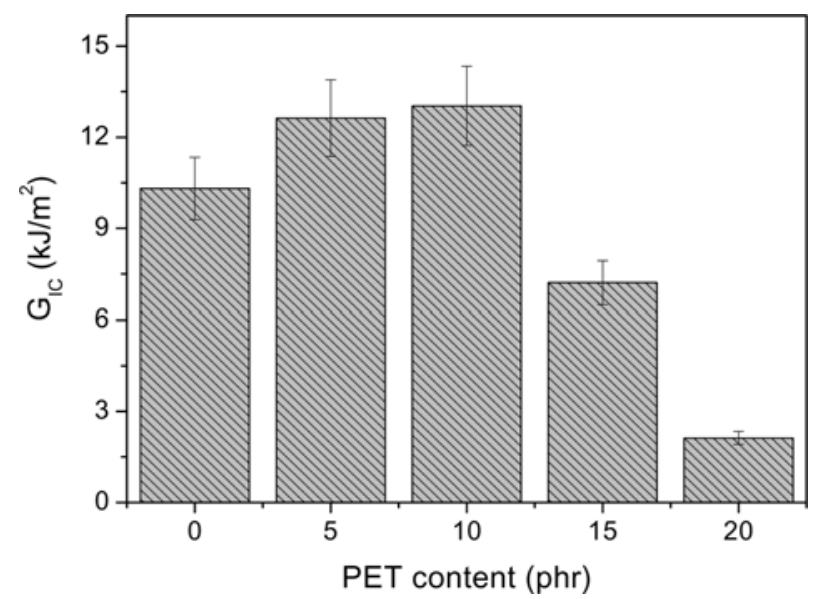

Figure 7. $G_{I C}$ values of DGEBA/PET blend system as a function of PET content.

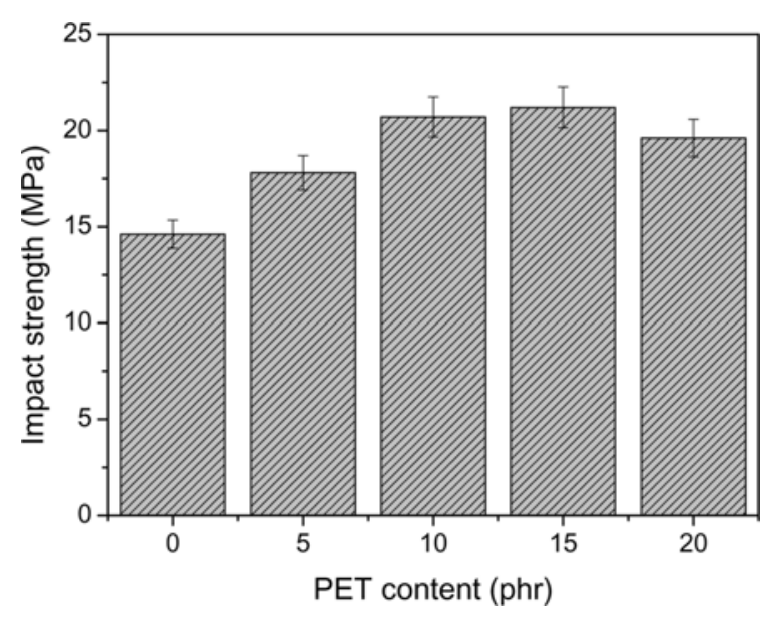

Figure 8. Impact strength values of DGEBA/PET blend system as a function of PET content.

of the blend system show a maximum value at $10 \mathrm{phr}$ of PET content. And the impact strengths of the DGEBA/PET blends with various PET contents are shown in Figure 8. As can be seen, the impact strength of DGEBA is significantly improved by the addition of PET. The neat DGEBA was brittle (14.6 MPa), whereas DGEBA containing $15 \mathrm{phr}$ PET was about $45 \%$ higher $(21.2 \mathrm{MPa})$. These results can be attributed to the increase of cross-linking density of the blend system by interaction between epoxy group of DGEBA and carboxyl group of PET, ${ }^{24}$ and PET act as stress concentrators to absorb the external energy to depress the crack growth. However, at relatively high content of PET, the network formation of the blend system may become worse so that it can ultimately decrease their mechanical properties.

Scanning electron micrographs (SEM) of the blend system for the fractured surfaces after the fracture toughness tests are shown in Figure 9. The fracture surface of the neat DGEBA is smooth and featureless, representing brittle fail-
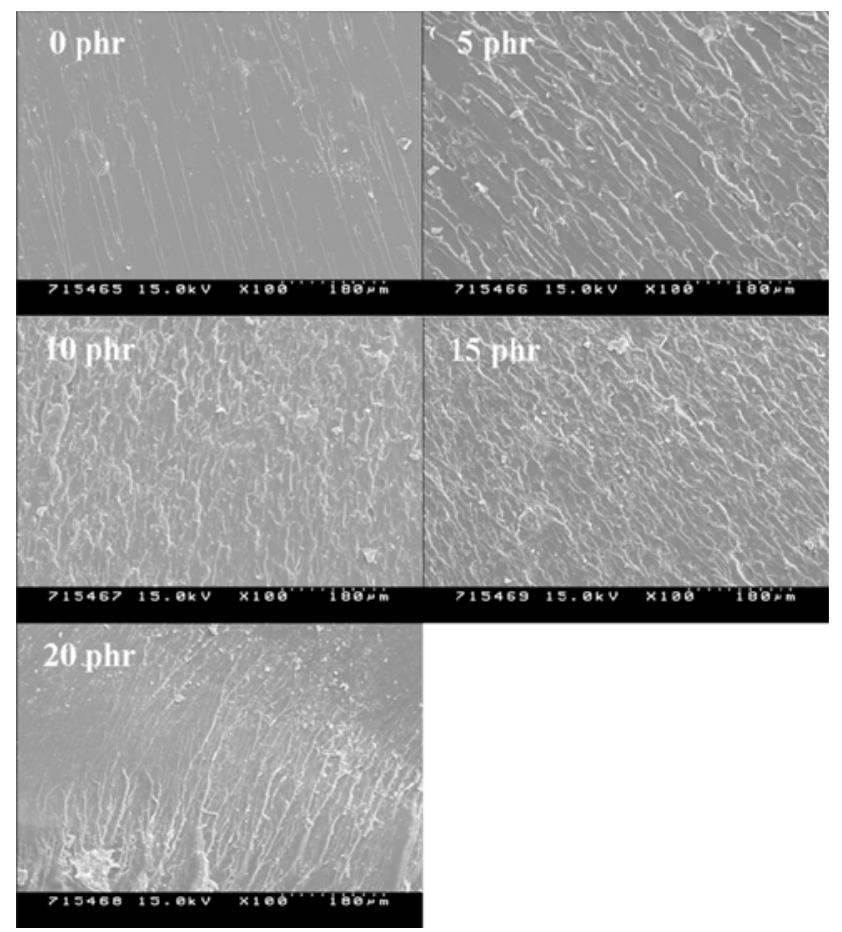

Figure 9. SEM microphotograph of the fracture surface of DGEBA/ PET blend system after $K_{I C}$ tests.

ure of homogenous material. As shown in the SEM images for the blend system, the fracture surfaces are remarkably different from that of neat DGEBA sample. The fracture surfaces of the blend system are broken into rough fracture pieces, contributing to the improvement of the toughness of the blend systems.

\section{Conclusions}

In this work, the influence of PET content on dielectric characteristics, cure behaviors, and mechanical interfacial properties of the blend system was studied. As a result, the cure activation energies increased in $10 \mathrm{phr}$ of PET with neat DGEBA. The dielectric constant of the blend system gradually decreased with increasing PET content. This is caused by the low dielectric constant of the PET. In the case of fracture toughness, it was observed that both $K_{I C}$ and $G_{I C}$ of the blend system increased with the PET addition and had a maximum value at $10 \mathrm{phr}$ of PET content. The increased cure activation energies and mechanical properties could be attributed to the strong intermolecular interaction between DGEBA and PET.

\section{References}

(1) L. F. Thompson, C. G. Willson, and S. Tagawa, Polymers for Microelectronics: Resists and Dielectrics, ACS Symposium, Washington, DC, 1994, No. 537. 
(2) J. Seo, W. Jang, and H. Han, Macromol. Res., 15, 10 (2007).

(3) F. L. Jin and S. J. Park, Polym. Int., 57, 577 (2008).

(4) Y. Choe, M. Kim, and W. Kim, Macromol. Res., 11, 267 (2003).

(5) R. S. Bauer, Epoxy Resin Chemistry, Advanced in Chemistry Series, American Chemical Society, Washington DC, 1979, No. 114.

(6) C. A. May, Epoxy resins, New York, Marcel Dekker, 1998.

(7) S. J. Park, T. J. Kim, and H. Y. Kim, Polym. Int., 51, 386 (2002).

(8) S. J. Park, H. Y. Lee, M. Han, and S. K. Hong, J. Colloid Interf. Sci., 270, 288 (2004).

(9) S. M. Choi, E. K. Lee, and S. Y. Choi, Elastomer(Korea), 43, 147 (2008)

(10) J. L. Han, S. M. Tseng, J. H. Mai, and K. H. Hsieh, Angew. Makromol. Chem., 181, 193 (1990).

(11) C. Fei and D. C. Wayne, Eur. Polym. J., 44, 1796 (2008).

(12) J. Lee, G. R. Yandek, and T. Kyu, Polymer, 46, 12511 (2005).

(13) F. L. Jin and S. J. Park, Polym. Degrad. Stabil., 92, 509 (2007).

(14) C. S. Zhao, F. L. Huang, W. C. Xiong, and Y. Z. Wang, Polym.
Degrad. Stabil., 93, 1188 (2008).

(15) Y. H. Shin, W. D. Lee, and S. S. Im, Macromol. Res., 15, 662 (2007).

(16) J. Bandyopadhyay, S. S. Ray, and M. Bousmina, J. Ind. Eng. Chem., 13, 614 (2007).

(17) S. J. Park, J. S. Jin, J. R. Lee, and P. K. Pak, Polymer(Korea), 24, 245 (2000).

(18) H. E. Kissinger, Anal. Chem., 29, 1072 (1957).

(19) E. S. Freeman and B. Carroll, J. Phys. Chem., 62, 394 (1958).

(20) A. R. Von Hippel, Dielectric Materials and Applications, Artech House Pub., New York, 1954.

(21) F. P. La Mantia, R. Schifani, and D. Aciemo, J. Appl. Polym. Sci., 28, 3075 (1983).

(22) S. J. Park, D. I. Seo, and C. W. Nah, J. Colloid Interf. Sci., 251, 225 (2002).

(23) R. P. Smith, D. Li, D. W. Francis, J. Chappuis, and A. W. Neumann, J. Colloid Interf. Sci., 157, 478 (1993).

(24) H. Zhang, S. Sun, M. Ren, Q. Chen, J. Song, H. Zhang, and Z. Mo, J. Appl. Polym. Sci., 109, 4082 (2008). 